\title{
Malignant myoepithelioma of the hard palate: 9-year follow-up
}

\section{Lucas Gomes Patrocinio ${ }^{1}$, Priscila Garcia Damasceno ${ }^{2}$, José Antonio Patrocinio ${ }^{3}$}

\author{
Keywords: myoepithelioma, head and neck neoplasms, \\ hard palate.
}

\section{INTRODUCTION}

Myoepitheliomas are rare tumors that represent about $1 \%$ of the salivary gland tumors ${ }^{1}$. Most of them are benign, and only $10 \%$ are malignant, and the latter are called malignant myoepitheliomas or myoepithelial carcinomas ${ }^{1}$. The first case of a malignant myoepithelioma was described in 1975 , since then there has been a greater incidence of these tumors reported in the parotid gland ${ }^{1}$. Its involvement of the hard palate is extremely rare, and there are only 8 cases reported in the world literature and with short term follow up ${ }^{1-6}$.

The present investigation reports a case of a patient with a malignant myoepithelioma on the hard palate, with bone destruction, successfully operated upon.

\section{CASE REPORT}

R.A., male, 38 years old, complaining of nasal obstruction for years, associated with running nose and recurrent epistaxis. During exam we noticed a palate tumor extending to the right-side nasal cavity. Computerized tomography (CT) showed a large solid mass occupying part of the right maxillary sinus, palate and nasal cavity (Fig. 1).

He was submitted to a transoral resection of the tumor, which pathology exam showed a tissue neoformation made up of ovoid cells of clear cytoplasm with round nuclei and, sometimes, spindle-shaped cells with areas of stromal hyalinization

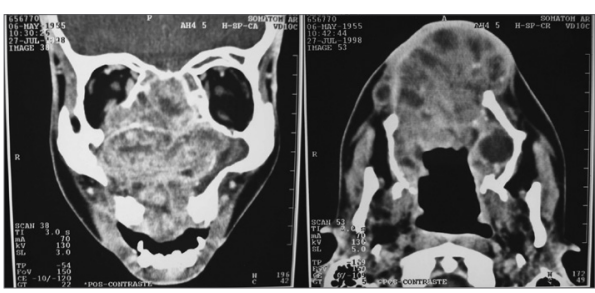

Figure 1. CT scan showing a large solid mass occupying part of the right-side maxillary sinus, palate and nasal cavity. and cystic formations. Immunohistochemistry analysis was positive for 14 cytokeratin, vimentin and specific muscle actin, which result matches the description of a malignant myoepithelioma. He had two new recurrences, also treated surgically.

We made him a palate closure prosthesis as a means for functional reconstruction. He has been under follow up for nine years, without signs of recurrence.

\section{DISCUSSION}

Malignant myoepitheliomas are rare tumors made up of atypical myoepithelial cells with high mitotic activity and aggressive growth1. Such tumors may stem from the differentiation of a benign tumor, it can stem from a benign tumor or it may recur which is the most frequent situation ${ }^{2,3}$.

The parotid gland is the most common tumor location, followed by the palate and the submandibular gland ${ }^{1}$. There is no gender predominance and the mean age is 62 years $^{1}$. It is usually painless, which delays diagnosis1. Malignant myoepitheliomas are characterized by local invasion and destruction, and it rarely metastasizes, and when they do, they involve lungs, liver, bones and lymphnodes ${ }^{4}$.

Histologically, the malignant myoepithelioma is characterized by pleomorphism, occasionally with eosinophilic cytoplasm, a high mitotic rate and usually with necrosis 5 . There are many architectural patterns (solid, myxoid and reticular) and different cell types: spindle, epithelioid, plasmocytoids and clear cells $s^{5,6}$.

Differential diagnosis includes leiomyosarcoma, peripheral nerve sheath nerve tumor, synovial sarcoma and metastatic melanoma, and immunohistochemistry is fundamental do differentiate them 5 . It shows constant positiveness for the S100 protein, vimentin and cytokeratin antibodies $^{3}$. Cytokeratin expression is variable in spindle-cell tumors ${ }^{3}$. The specific muscle actin immunoreaction varies according to cell phenotype ${ }^{3}$.

The treatment advocated is tumor surgical resection with margins; however, before such procedure, an image exam must be carried out in order to assess the extension and involvement of neighboring structures $^{1,2}$. In the literature studied, all the cases were treated by surgical resection, and the outcomes were favorable.

\section{CONCLUSIONS}

The malignant soft palate myoepithelioma is an extremely hard tumor. Its treatment continues being broad resection. The long patient follow up described in the present case corroborates literature data.

\section{REFERENCES}

1.Nagao T, Sugano I, Ishida Y, Tajima Y, Matsuzaki O, Konno A, Kondo Y, Nagao K. Salivary gland malignant myoepithelioma: a clinicopathologic and immunohistochemical study of ten cases. Cancer. 1998;83(7):1292-9.

2.Karatzanis AD, Drivas EI, Giannikaki ES, Lachanas VA, Hatziioannou JK, Velegrakis GA. Malignant myoepithelioma arising from recurrent pleomorphic adenoma of the soft palate. Auris Nasus Larynx. 2005;32(4):435-7.

3.Bombi JA, Alos L, Rey MJ, Mallofre C, Cuchi A, Trasserra J, Cardesa A. Myoepithelial carcinoma arising in a benign myoepithelioma: immunohistochemical, ultrastructural, and flow-cytometrical study. Ultrastruct Pathol. 1996;20(2): 145-54.

4.Chhieng DC, Paulino AF. Cytology of myoepithelial carcinoma of the salivary gland. Cancer. 2002;96(1):32-6.

5.Kuwabara H, Uda H, Miyabe K, Saito K, Shibanushi T. Malignant plasmacytoid myoepithelioma of the palate: histological observations compared to benign predominant plasmacytoid myoepithelial cells in pleomorphic adenoma of the palate. Ultrastruct Pathol. 1998;22(2):153-60.

6.Kuwabara H, Kohno K, Kishida F, Uda H, Miyabe K, Nagao K, Saito K, Shibanushi T. Imprint cytology of malignant plasmacytoid myoepithelioma of the palate. Acta Cytol. 1998;42(2):440-3

Otolaryngologist and Craniofacial Surgeon, Head of the Craniofacial Division of the Otorhinolaryngology Ward - Medical School of the Federal University of Uberlândia 2MD. ENT resident - Otorhinolaryngology Ward - Medical School of the Federal University of Uberlândia ${ }^{3}$ Full Professor - Chairman - Otorhinolaryngology Ward - Medical School of the Federal University of Uberlândia.

Serviço de Otorrinolaringologia da Faculdade de Medicina da Universidade Federal de Uberlândia, Uberlândia, Minas Gerais, Brasil.

Send correspondence to: Lucas Gomes Patrocinio - Rua Arthur Bernardes 555 1o. andar Uberlândia MG 38400-368. Tel/Fax: (0xx34) 3215-1143 - E-mail: lucaspatrocinio@triang.com.br

Paper submitted to the BJORL-SGP (Publishing Management System - Brazilian Journal of Otorhinolaryngology) on June 15, 2007; and accepted on August 11, 2007. cod. 4610 